\title{
Factors Affecting Survival After Mastectomy in Invasive Lobülar Carcinoma of the Breast
}

\section{İnvaziv Lobüler Meme Kanserinde Mastektomi Sonrası Sağkalımı Etkileyen Faktörler}

\author{
Kaptan Gülben ${ }^{1}$, Ali Uğur Berberoğlu ${ }^{1}$ \\ ${ }^{1}$ Ankara Onkoloji Eğitim Ve Araştırma Hastanesi, Genel Cerrahi Kliniği, Ankara, Türkiye.
}

Dergiye Ulaşma Tarihi:31.10.2015 Dergiye Kabul Tarihi:12.11.2015 Doi: $\quad$ 10.5505/aot.2015.46362

\section{ÖZET}

Giriş ve Amaç: İnvaziv lobüler karsinoma meme kanserinin ikinci en sık görülen histolojik tipi olmasına rağmen, klinikopatolojik özelliklerinin prognostik önemi halen tartışmalıdır. Bu çalışmanın amacı invaziv lobüler meme karsinomalı hastalarda mastektomi sonrası hastalıksız sağkalımı etkileyen faktörleri tanımlamaktır.

Yöntem ve Gereçler: 2006-2011 yılları arasında modifiye radikal mastektomi ile tedavi edilen invaziv lobüler karsinomalı 68 hastanın kayıtları geriye dönük olarak değerlendirildi. Yaş, menopoz durumu, patolojik tümör boyutu, patolojik lenf nodu durumu, grade, patolojik evre, lenfovasküler invazyon, östrojen reseptörü, progesteron reseptörü ve human epidermal growth faktör reseptör-2 durumunun hastalıksız sağkalım üzerindeki etkisi tek ve çok değişkenli analizlerle incelendi.

Bulgular: Ortanca takip süresi 49 ay (21-83 ay) idi. Beş yıllık genel sağkalım \%92, 5-yıllık hastalıksız sağkalım ise $\% 85$ olarak bulundu. Bir hastada lokal nüks $(\% 1,5), 9$ hastada uzak metastaz $(\% 13,2)$ geliştiği, 4 hastanın da kaybedildiği $(\% 5,9)$ belirlendi. Tek değişkenli analizde tümör boyutu, lenf nodu durumu, evre, lenfovasküler invazyon, östrojen reseptörü ve progesteron reseptörü durumunun hastalıksız sağkalım üzerinde anlamlı etkiye sahip olduğu saptandı. Çok değişkenli analizde ise, bu faktörlerden tümör boyutu (Hazard ratio $[\mathrm{HR}]=6,4, \% 95$ güven aralığ1 $[\mathrm{GA}]=1,2-21,2, \mathrm{P}=0,001)$ ve lenf nodu durumunun $(\mathrm{HR}=4,8, \% 95 \mathrm{GA}=1,1-15,4, \mathrm{P}=0,01)$ hastalıksız sağkalım için bağımsız risk faktörleri olduğu belirlendi.

Tartışma ve Sonuç: Tümör çapı $4 \mathrm{~cm}$.den büyük ve aksiller lenf nodu pozitif olan invaziv lobüler meme kanserli hastalarda hastalıksız sağkalım daha kötüdür.

Anahtar Kelimeler: Meme kanseri, infiltratif lobüler karsinoma, özel tip, mastektomi, prognostik faktörler.

\begin{abstract}
Introduction: Although invasive lobular carcinoma is the second most common histotype of breast cancer, the prognostic implications of its clinicopathologic characteristics remain controversial. The aim of this study was to identify the factors affecting disease-free survival after mastectomy in patients with invasive lobular carcinoma.

Methods: The records of 68 patients with invasive lobular carcinoma treated with modified radical mastectomy between 2006 and 2011 were retrospectively evaluated. The effects of age, menopausal status, pathological tumor size, pathological lymph node status, histological grade, pathological stage, lymphovascular invasion, estrogen receptor status, progesterone receptor status, and human epidermal growth factor receptor-2 status on disease-free survival were examined by univariate and multivariate statistical analyses.

Results: The median follow-up time was 49 months (range 21 to 83). Five-year overall survival and disease-free survival rates were $92 \%$ and $85 \%$, respectively. One patient had local recurrence $(1.5 \%)$ and distant metastasis developed in 9 patients (13.2\%). Four patients died during follow-up period (5.9\%). In univariate analysis, tumor size, lymph node status, stage, lymphovascular invasion, estrogen receptor status, and progesterone receptor status had significant effect on disease-free survival. Of these, tumor size (hazard ratio $[\mathrm{HR}]=6,4 ; 95 \%$ confidence interval $[\mathrm{CI}]=1,2-21,2 ; \mathrm{P}=0,001)$ and nodal status $(\mathrm{HR}=4,8 ; 95 \% \mathrm{CI}=1,1-15,4 ; \mathrm{P}=0,01)$ were determined as independent risk factors on disease-free survival in multivariate analysis.

Discussion and Conclusion: Disease-free survival in invasive lobular breast cancer patients who have tumor size greater than $4 \mathrm{~cm}$ and positive axillary lymph node is worse.
\end{abstract}

Key words: Breast cancer, infiltrating lobular carcinoma, special type, mastectomy, prognostic factors. 


\section{Giriş}

Memenin invaziv lobüler karsinoması (İLK) ilk kez 1941 yılında Foot ve Stewart tarafindan tanımlanmış (1), daha sonra 1970'ler ve 1980'lerde alveoler, solid, pleomorfik, taşl1 yüzük, histiyositoid ve apokrin olmak üzere farklı alt tipleri bildirilmiştir (2-4). Meme kanserleri içinde invaziv duktal kanserden (IDK) sonra en s1k görülen ikinci histolojik tip İLK olup, tüm meme kanserlerinin \%5-15'ini oluşturur (5). İLK insidansı özellikle postmenopozal kadınlarda olmak üzere giderek artmaktadır ve bu durum kismen hormon replasman tedavisiyle ilişkilendirilmektedir $(6,7)$. İLK ayrı bir kitleden çok, meme dokusunda güçlükle belirlenebilen bir kalınlaşma şeklinde göründüğü için klinik muayene ve mamografi ile erken tanınması zorluk arz eder (8).

İLK, İDK ile kıyaslandığında; tanı anında yüksek yaş, büyük tümör boyutu, multisentrisite, multifokalite, bilateralite, hormon reseptör pozitifliği, human epidermal growth faktör reseptör 2 (HER2) negatifliği, düşük hücre proliferasyon oranı ve düşük kemoterapi cevabı ile daha sık ilişkilidir (910). Tüm bunlara rağmen tedavi yöntemleri duktal kökenli meme kanserleriyle benzerdir. İLK'nin prognozu halen tartışmalıdır. Bazı yazarlar prognozunun İDK'den daha iyi (11), bazıları ise daha kötü olduğunu belirtmektedir (10). Kısa süreli takipler sonucunda IDK ile eşit veya biraz daha iyi prognozlu olduğu, uzun dönem takipler sonucunda ise geç rekürrenslerin ve daha kötü prognoza eğilimin arttığ1 bildirilmektedir (8-10). Prognozu etkileyebilecek faktörler arasında yaş, tümör boyutu, aksiller lenf nodu durumu, östrojen reseptör (ER) ve progesteron reseptör (PR) durumu, histolojik grad ve HER2 en fazla irdelenen etkenlerdir.

$\mathrm{Bu}$ çalışmanın amacı, İLK tanısı ile mastektomi uygulanarak adjuvan tedavilerini tamamlayan meme kanserli hastalarda hastalıksız sağkalımı etkileyen klinik ve patolojik faktörleri değerlendirmektir.

\section{Gereç ve Yöntem}

Merkezimizde Haziran 2006 ile Aralık 2011 tarihleri arasında cerrahi olarak tedavi edilen 1120 meme kanserli hastanın kayıtları geriye dönük olarak değerlendirildi. Toplam 79 hastanın ILK histolojik tipine sahip olduğu görüldü. Bunlardan neoadjuvan tedavi almamış, tanı anında uzak metastazı, bilateral meme kanseri, başka primer kanseri olmayan ve modifiye radikal mastektomi uygulanmış 68 hasta çalışmaya dahil edildi. Çalışma için hastane eğitim planlama kurulunun onayı alınd1.

Patolojik evreleme 2010 AJCC (American Joint Committee on Cancer) kriterlerine göre yapıldı (12). Buna göre hastaların pT1-3, pN13, M0 tümör özelliklerine sahip olduğu saptand. Cerrahi tedavi sonrasi endikasyon dahilinde hastalara adjuvan olarak ortalama 50 Gy eksternal radyoterapi uygulandığı, ağırlıklı olarak antrasiklin ve taksan içeren sistemik tedavi protokollerinin verildiği, HER2+ kabul edilen hastaların da hedefe yönelik tedavi aldığ 1 tespit edildi. Hormon reseptörü pozitif hastaların menopoz durumlarına göre beş yıl veya daha uzun süreli tamoksifen ve/veya aromataz inhibitörü aldığı belirlendi.

Patolojik incelemede hormon reseptörleri belirlenirken, parafin bloklarda tümör hücrelerinde $\% \quad 1$ 'den fazla immünohistokimyasal boyanma olması durumu reseptör pozitif olarak kabul edildi. İmmünohistokimyasal olarak skor $3+$ veya FISH/SISH+ hastalar ise HER2+ olarak kabul edildi.

Klinikopatolojik faktörlerden yaş, menopoz, patolojik tümör boyutu (pT), patolojik lenf nodu (pN), histolojik grad, patolojik evre, lenfovasküler invazyon (LVI), ER, PR ve HER2 durumunun hastalıksız sağkalım üzerindeki etkisi istatistiksel olarak değerlendirildi. Tek ve çok değişkenli analiz için Cox-oransal risk modeli kullanıldı. Hastalıksız ve genel sağkalım oranları KaplanMeier yöntemi ile hesapland, $\mathrm{P}<0,05$ değeri istatistiksel olarak anlaml kabul edildi. İstatistik testleri "Statistical Package for the Social Sciences, version 15.0 for Windows (SPSS Inc., Chicago, IL, USA)" programıla yapıld1.

\section{Sonuçlar}

Cerrahi ile tedavi edilen toplam 1120 meme kanserli hastanın \%7'sinde İLK olduğu saptandi. Tüm hastalara preoperatif olarak bilateral mamografi çekildiği belirlendi. Karşı memesinde kuşkulu görüntüleme bulgusu olan dokuz hastaya biyopsi yapılarak malignitenin 
ekarte edildiği tespit edildi. Hastaların klinik ve patolojik özellikleri Tablo 1'de verilmiştir. Ortanca yaş 48 (30-80 yaş), ortanca takip süresi 49 ay (21-83 ay) idi. Bilateral meme kanserli olgular çalışma dışı bırakıldığından Ortanca tümör boyutunun $2,5 \mathrm{~cm}(0,5-6 \mathrm{~cm})$, 53 hastada $4 \mathrm{~cm}$ ve altında (\%78), 15 hastada ise $4 \mathrm{~cm}$.den büyük (\%22) olduğu saptand. Aksilladan disseke edilen ortanca lenf nodu sayısının 24 (10-48), ortanca metastatik lenf nodu sayısının ise 4 (1-18) olduğu belirlendi. On beş hastada (\%22) multifokal veya multisentrik tümör olduğu tespit edildi.

Hastaların postoperatif \%52'sinin RT, \%84'ünün KT, \% 12'sinin hedefe yönelik tedavi, \%72'sinin ise HT aldığ 1 saptandi. Takip süresinde bir hastada lokal nüks $(\% 1,5)$, beş hastada izole kemik, bir hastada kemik+akciğer, bir hastada kemik+beyin, iki hastada da izole akciğer olmak üzere toplam dokuz hastada uzak metastaz $(\% 13,2)$ geliştiği saptand. Dört hastanın takipler sirasinda öldüğü $(\% 5,9)$ belirlendi. $\mathrm{Bu}$ hastalardan üçünün hastalığa bağlı uzak metastaz, birinin ise hastalık dışı nedenle öldüğü belirlendi. Beşyıllık genel ve hastalıksız sağkalım oranları sirasiyla $\% 92$ ve $\% 85$ olarak bulundu (Şekil1). Ortanca hastalıksız sağkalım süresi 45 ay (8-78 ay) olarak saptandi.

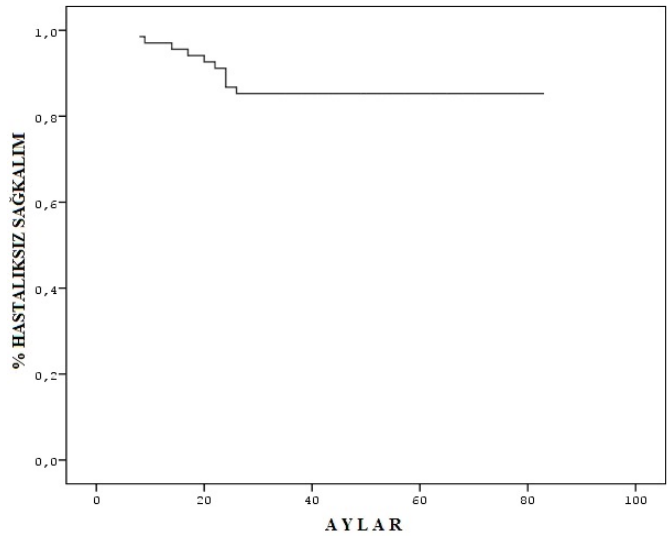

Şekil-1: Kaplan-Meier hastalıksız sağkalım eğrisi.

Tablo-1: Hastaların klinik ve patolojik özellikleri

\begin{tabular}{|c|c|c|c|}
\hline \multicolumn{2}{|c|}{ DEĞISSKENN } & $\mathrm{n}$ & $\%$ \\
\hline \multirow[t]{2}{*}{ Yaş } & $\leq 40$ & 15 & 22 \\
\hline & $>40$ & 53 & 78 \\
\hline \multirow[t]{2}{*}{ Menopoz } & Pre & 32 & 47 \\
\hline & Post & 36 & 53 \\
\hline \multirow[t]{3}{*}{$\mathrm{pT}(\mathrm{cm})$} & $\mathrm{T} 1(\leq 2)$ & 26 & 38 \\
\hline & $\mathrm{T} 2(2,1-5)$ & 32 & 47 \\
\hline & $\mathrm{T} 3(>5)$ & 10 & 15 \\
\hline \multirow[t]{4}{*}{$\mathrm{pN}$} & $\mathrm{pNO}$ & 33 & 48 \\
\hline & $\mathrm{pN1}$ & 12 & 18 \\
\hline & $\mathrm{pN2}$ & 10 & 15 \\
\hline & $\mathrm{pN3}$ & 13 & 19 \\
\hline \multirow[t]{3}{*}{ Histopatolojik grad } & $\mathrm{I}$ & 7 & 10 \\
\hline & II & 23 & 34 \\
\hline & III & 38 & 56 \\
\hline \multirow[t]{2}{*}{ LVİ } & Yok & 45 & 66 \\
\hline & Var & 23 & 34 \\
\hline \multirow[t]{2}{*}{ ER } & Pozitif & 48 & 71 \\
\hline & Negatif & 20 & 29 \\
\hline \multirow[t]{2}{*}{ PR } & Pozitif & 40 & 59 \\
\hline & Negatif & 28 & 41 \\
\hline \multirow[t]{2}{*}{ HER2 } & Pozitif & 8 & 12 \\
\hline & Negatif & 60 & 88 \\
\hline \multirow[t]{3}{*}{ Patolojik evre } & I & 17 & 25 \\
\hline & II & 25 & 37 \\
\hline & III & 26 & 38 \\
\hline \multirow[t]{2}{*}{ Radyoterapi } & Yok & 33 & 48 \\
\hline & Var & 35 & 52 \\
\hline \multirow[t]{2}{*}{ Kemoterapi } & Yok & 11 & 16 \\
\hline & Var & 57 & 84 \\
\hline \multirow[t]{2}{*}{ Hormonoterapi } & Yok & 19 & 28 \\
\hline & Var & 49 & 72 \\
\hline
\end{tabular}

pT: patolojik tümör boyutu, pN: patolojik lenf nodu, LVİ: lenfovasküler invazyon, ER: östrojen reseptörü, PR: progesteron reseptörü, HER2: human epidermal growth faktör reseptör-2. 
Tablo-2: Hastalıksız sağkalımı etkileyen faktörlerin tek değişkenli analizi.

\begin{tabular}{|ll|c|c|c|}
\hline Değişken & & P değeri & HR & \%95 GA \\
\hline Yaş & ( $\leq 40$ vs. $>40)$ & $>0,05$ & - & - \\
\hline Menopoz & (pre vs. post) & $>0,05$ & - & - \\
\hline pT & ( $\leq 4 \mathrm{~cm}$ vs. $>4 \mathrm{~cm})$ & 0,001 & 6,2 & $1,4-32,3$ \\
\hline pN & (negatif vs. pozitif) & 0,001 & 5,3 & $1,2-22,6$ \\
\hline Patolojik evre & (I-II vs. III) & 0,02 & 3,8 & $1,1-14,8$ \\
\hline Histolojik grad & (I-II vs. III) & $>0,05$ & - & - \\
\hline LVI & (yok vs. var) & 0,03 & 3,2 & $1,1-9,8$ \\
\hline ER & (pozitif vs. negatif) & 0,03 & 3,6 & $1,4-13,4$ \\
\hline PR & (pozitif vs. negatif) & 0,04 & 2,8 & $1,2-11,8$ \\
\hline HER2 & (negatif vs. pozitif) & $>0,05$ & - & - \\
\hline
\end{tabular}

HR: hazard ratio, GA: güven aralığı, diğer kısaltmalar Tablo-1'deki gibidir.

Tablo-3: Hastalıksız sağkalımı etkileyen faktörlerin çok değişkenli analizi.

\begin{tabular}{|ll|c|c|c|}
\hline Değişken & & P değeri & HR & \%95 GA \\
\hline pT & $(\leq 4 \mathrm{~cm}$ vs. $>4 \mathrm{~cm})$ & 0,001 & 6,4 & $1,2-21,2$ \\
\hline pN & (negatif vs. pozitif) & 0,01 & 4,8 & $1,1-15,4$ \\
\hline Patolojik evre & (I-II vs. III) & $>0,05$ & - & - \\
\hline LVI & (yok vs. var) & $>0,05$ & - & - \\
\hline ER & (pozitif vs. negatif) & $>0,05$ & - & - \\
\hline PR & (pozitif vs. negatif) & $>0,05$ & - & - \\
\hline
\end{tabular}

Kisaltmalar Tablo-1 ve 2'deki gibidir.

Tek değişkenli analizde (Tablo-2) yaş, menopoz, histolojik grad ve HER2 durumunun hastalıksız sağkalımı anlamlı etkilemediği ( $p>0,05)$, ancak pT, pN, evre, LVİ, ER ve PR durumunun hastalıksız sağkalım için anlamlı risk faktörleri olduğu $(\mathrm{p}<0,04)$ tespit edildi. Çok değişkenli analizde ise (Tablo-3) pT $>4$ $\mathrm{cm}$ olmas1 (hazard ratio $[\mathrm{HR}]=6,4, \% 95$ güven aralığ1 $[\mathrm{GA}]=1,2-21,2, \quad \mathrm{P}=0,001)$ ve $\mathrm{pN}$ pozitifliği $\quad(\mathrm{HR}=4,8, \quad \% 95 \quad \mathrm{GA}=1,1-15,4$, $\mathrm{P}=0,01)$ hastalıksız sağkalımı olumsuz etkileyen bağımsız risk faktörleri olarak belirlendi.

\section{Tartışma}

İLK, tüm meme kanserlerinin \%5-15'ini oluşturur ve İDK'den sonra memenin en sik görülen ikinci kanseridir (5). Bu çalışmada yaklaşık beş yıllık süre aralığında tedavi edilen meme kanserli hastaları \%7'sini İLK histolojik tipinin oluşturduğu saptandı ve bu oran literatür ile uyumlu bulundu.
Memenin ILLK'sinda prognozun IDK'den farklı olup olmadığı halen bir tartışma konusudur. $\mathrm{Bu}$ tartışmalara rağmen her iki histolojik tipte de prognozu etkileyen faktörler ve tedavi protokolleri genellikle benzerdir. Ancak İLK'nın tanı anında yüksek yaş, büyük tümör boyutu, multisentrisite, multifokalite, bilateralite, hormon reseptör pozitifliği, HER2 negatifliği gibi faktörlerle daha sik ilişkili olduğu bildirilmektedir (9-10).

Meme kanserinde yaş, tümör çapı, lenf nodu metastazı, ER, PR, histolojik grad ve HER2 durumu prognoz ve adjuvan tedavi kararının değerlendirilmesinde önemli faktörler olarak kabul edilmektedir (13). Bizim çalışmamızda hastaların yaklaşık olarak \%80'i 40 yaş üzerinde olup, yaş hastalıksız sağkalım için bir risk faktörü olarak saptanmadı. Histolojik grad IDK için bir risk faktörü olarak bilinmesine rağmen, İLK için prognostik önemi konusundaki bilgiler daha azdır (14). Bu çalışmada histolojik grad, hastalıksız sağkalım için anlamlı bir risk faktörü olarak bulunmadı. Aynı şekilde tümörün ER, PR ve LVİ durumu 
tek değişkenli analizde birer risk faktörü olmalarına rağmen, çok değişkenli analizde hastalıksız sağkalım üzerinde anlamlı etkilerinin olmadığ $\mathrm{b}$ belirlendi.

Sunulan çalışmada 5-yıllık hastalıksız sağkalım oranı $\% 85$ olarak saptanmıș olup bu oran literatürle de uyumlu görünmektedir (15). Yapılan çalışmalarda, İLK için tümör boyutu ve aksiller lenf nodu metastazının en güçlü prognostik faktörler olduğu belirtilmektedir. $(8,14-16)$. Sunulan çalışma da, invaziv lobüler meme kanserinde tümör boyutu ve aksiller lenf nodu metastazının hastalıksız sağkalım için bağımsız prognostik faktörler olduğunu göstermektedir. Hastaların \%22'sinde patolojik tümör çapının $4 \mathrm{~cm}$.den daha büyük ve bu hastalarda hastalıksız sağ kalımın yaklaşık altı kat daha olumsuz etkilendiği saptanmıştır. Diğer yandan, hastaların \%52'sinde aksiller lenf nodlarına metastaz geliştiği ve bu hastalarda da beş kat kadar daha olumsuz hastalıksız sağkalım görüldüğü belirlenmiştir. Bir proliferasyon belirteci olan Ki-67, $2009 \mathrm{St}$ Gallen kılavuzlarında önemli bir prognostik faktör olarak sunulmuştur (17). Ancak Ki67'nin ILLK için uzun dönem prognostik değeri konusunda yeterince çalışma yoktur. Bazı çalışmalarda Ki-67, histolojik grad ve östrojen reseptörü kombinasyonundan oluşan bir indeksin (KiGE indeksi) tüm histolojik alt tipler için güçlü bir prognostik etkiye sahip olduğu gösterilmiştir (18-20).

Sonuç olarak bu çalışma, tümör çapı ve aksiller lenf nodu metastazının İLK için bağımsız prognostik faktörler olduğunu göstermektedir. $\mathrm{Bu}$ da hastalığın erken tanı ve tedavisinin önemine işaret eder.

\section{Çıkar Çatışması: Yok}

\section{Kaynaklar}

1. Foote FW Jr, Stewart FW. Lobülar carcinoma in situ: a rare form of mammary cancer. Am J Pathol. 1941;17:491-6

2. Martinez V, Azzopardi JG. Invasive lobülar carcinoma of the breast: incidence and variants. Histopathology. 1979;3:467-88

3. Fechner RE. Histologic variants of infiltrating lobülar carcinoma of the breast. Hum Pathol. 1975;6:373-8.

4. Rosen PP. Rosen's Breast Pathology. 2nd ed. Philadelphia: Lippincott, Williams \& Wilkins; 2001:627-38

5. Lakhani SR, Ellis IO, Schnitt SJ, Tan PH, van de Vijver MJ. WHO classification of tumours of the breast. 4th ed. Geneva:WHO press, 2012
6. Li CI, Anderson BO, Daling JR, Moe RE. Trends in incidence rates of invasive lobülar and ductal breast carcinoma. JAMA 2003;289:1421-4

7. Biglia N, Mariani L, Sgro L, Mininanni P, Moggio G, Sismondi P. Increased incidence of lobülar breast cancer in women treated with hormone replacement therapy: implications for diagnosis, surgical and medical treatment. Endocr Relat Cancer 2007;14:549-67

8. Arpino G, Bardou VJ, Clark GM, Elledge RM. Infiltrating lobülar carcinoma of the breast: tumor characteristics and clinical outcome. Breast Cancer Res. 2004;6:149-56

9. Pestalozzi BC, Zahrieh D, Mallon E, Gusterson BA, Price KN, Gelber RD, Holmberg SB, Lindtner J, Snyder R, Thurlimann B, Murray E, Viale G, Castiglione-Gertsch M, Coates AS, Goldhirsch A; International Breast Cancer Study Group. Distinct clinical and prognostic features of infiltrating lobülar carcinoma of the breast: combined results of 15 International Breast Cancer Study Group clinical trials. J Clin Oncol 2008;26:3006-14

10. Rakha EA, El-Sayed ME, Powe DG, Green AR, Habashy H, Grainge MJ, Robertson JF, Blamey R, Gee J, Nicholson RI, Lee AH, Ellis IO. Invasive lobülar carcinoma of the breast: response to hormonal therapy and outcomes. Eur J Cancer 2008;44:73-83

11. Toikkanen S, Pylkkannen L, Joensuu H. Invasive lobülar carcinoma of the breast has better short- and long-term survival than invasive ductal carcinoma. $\mathrm{Br}$ J Cancer 1997; 76:1234-40

12. Edge SB, Byrd DR, Compton CC, Fritz AG, Greene FL, Trotti A., eds. AJCC Cancer Staging Manual, 7th ed. New York: Springer, 2010

13. Narbe U, Bendahl P, Grabau D, Rydén L, Ingvar C, Fernö M. Invasive lobülar carcinoma of the breast: long-term prognostic value of Ki67 and histological grade, alone and in combination with estrogen receptor. Springer Plus 2014,3:70

14. Rakha EA, El-Sayed ME, Menon S, Green AR, Lee $\mathrm{AH}$, Ellis IO. Histologic grading is an independent prognostic factor in invasive lobülar carcinoma of the breast. Breast Cancer Res Treat 2008;111:121-7

15. Orvieto E, Maiorano E, Bottiglieri L, Maisonneuve P, Rotmensz N, Galimberti İ, Luini A, Brenelli F, Gatti G, Viale G. Clinicopathologic characteristics of invasive lobülar carcinoma of the breast, results of an analysis of 530 cases from a single institution. Cancer 2008;113:1511-20

16. Wasif N, Maggard MA, Ko CY, Giuliano AE. Invasive lobülar vs. ductal breast cancer: a stagematched comparison of outcomes. Ann Surg Oncol 2010;17:1862-9

17. Goldhirsch A, Ingle JN, Gelber RD, Coates AS, Thurlimann B, Senn HJ. Thresholds of therapies: highlights of the St Galen International Expert Consensus on the primary therapy of early breast cancer Ann Oncol 2009;20:1319-29

18. Klintman M, Bendahl PO, Grabau D, Lövgren K, Malmström P, Fernö M. The prognostic value of Ki67 is dependent on estrogen receptor status and histological grade in premenopausal patients with node-negative breast cancer. Mod Pathol 2010;23:251-9

19. Strand C, Ahlin C, Bendahl PO, Fjällskog ML, Hedenfalk I, Malmström P, Fernö M. Combination of

Adress for correspondence: Doç.Dr.Kaptan Gülben, Kardelen Mah. 2040. Sok., B/27, Batkent. 06370 Ankara - Türkiye

e-mail: kgulben@yahoo.com

Available at www.actaoncologicaturcica.con

Copyright $\mathbb{C}$ Ankara Onkoloji Hastanes 
the proliferation marker cyclin A, histological grade, and estrogen receptor status in a new variable with high prognostic impact in breast cancer. Breast Cancer Res Treat 2012;131:33-40

20. Strand C, Bak M, Borgquist S, Chebil G, Falck AK, Fjällskog ML, Grabau D, Hedenfalk I, Jirström K,
Klintman M, Malmström P, Olsson H, Rydén L, Stål O, Bendahl PO, Fernö M. The combination of Ki67, histological grade and estrogen receptor status identifies a low-risk group among 1,854 chemo-naïve women with N0/N1 primary breast cancer. Springerplus 2013 Dec;2(1):111 